ИНСУЛИНОРЕЗИСТЕНТНОСТЬ ПРИ ОЖИРЕНИИ: ПРИЧИНЫ И ПОСЛЕДСТВИЯ

\author{
() Е.А. Лавренова*, О.М. Драпкина
}

Национальный медицинский исследовательский центр терапии и профилактической медицины, Москва, Россия

Распространенность ожирения в мире носит на сегодняшний день характер глобальной эпидемии. Являясь не только рецидивирующим, хроническим заболеванием, но и серьезным фактором риска, ожирение приводит к развитию и усугублению течения многих неинфекционных заболеваний. На фоне избытка и дисфункции жировой ткани при ожирении значительно возрастает риск развития таких заболеваний, как сахарный диабет 2 типа, артериальная гипертензия, атеросклероз, неалкогольная жировая болезнь печени и др. Основой патогенеза некоторых из них является развитие вторичной инсулинорезистентности. Механизмы влияния избытка жировой ткани на развитие резистентности к инсулину активно изучаются на протяжении последних десятилетий, однако до сих пор исследователями не получены ответы на все волнующие вопросы. В статье представлены основные механизмы развития инсулинорезистентности при ожирении и методы ее диагностики, а также актуальные данные исследований в ключе данной темы; рассмотрена тесная взаимосвязь инсулинорезистентности с развитием целого ряда ассоциированных с ожирением заболеваний, а именно - нарушениями углеводного обмена, дислипидемией, артериальной гипертензией, ишемической болезнью сердца, а также нарушениями репродуктивной функции как у женщин, так и у мужчин.

КЛЮЧЕВЫЕ СЛОВА: ожирение; абдоминальное ожирение; инсулинорезистентность; сахарный диабет; жировая ткань; инсулин; дислипидемия; неалкогольная жировая болезнь печени; бесплодие.

\title{
INSULIN RESISTANCE IN OBESITY: PATHOGENESIS AND EFFECTS
}

\author{
(c) Evgenia A. Lavrenova*, Oxana M. Drapkina
}

National Medical Research Center for Preventive Medicine, Moscow, Russia

The prevalence of obesity in the world is described as the global epidepic. Being not only a chronic recurrent disease but also a serious risk factor, obesity leads to the development and aggravation of many non-communicable diseases. Excessive amount and adipose tissue dysfunction in obesity determines the risk of the development of type 2 diabetes, arterial hypertension, atherosclerosis, non-alcoholic fatty liver disease etc. Secondary insulin resistance often underlies the development of the above mentioned conditions. The mechanisms contributing to the development of insulin resistance in case of excessive adipose tissue accumulation are being intensively investigated over the last decades, however many questions yet remain unsolved. In this article we present the key mechanisms underlying insulin resistance in obesity and diagnostic approaches for insulin resistance as well as the current data in this topic. The authors review the close links between insulin resistance and obesity related diseases, namely disorders of carbohydrate metabolism, dyslipidemia, arterial hypertension, coronary artery disease and reproductive disorders.

KEYWORDS: obesity; abdominal obesity; insulin resistance; diabetes; adipose tissue; insulin; dyslipidemia; nonalcoholic fatty liver disease; infertility; reproductive disorders.

\section{ВВЕДЕНИЕ}

Ожирение - хроническое рецидивирующее гетерогенное заболевание, которое развивается под влиянием генетических, физиологических факторов и факторов внешней среды и характеризуется избыточным накоплением жировой ткани, дисфункция которой приводит к многочисленным негативным последствиям.

Число людей с избыточной массой тела в современном мире увеличивается на 10\% каждые 10 лет. Это позволило определить ожирение как неинфекционную эпидемию. В англоязычных источниках часто можно встретить термин «Globesity» («глобальное ожирение»), который как нельзя более точно отражает остроту проблемы. По данным ВО3, на 2016 г. около 2 млрд человек
В мире имеют избыточную массу тела и около 650 млн из них страдают ожирением [1].

В России статистика также неутешительна. Каждый второй россиянин на сегодняшний день имеет избыточную массу тела. По данным многоцентрового эпидемиологического исследования ЭССЕ-РФ (2013 г.), 29,7\% россиян страдают ожирением. При этом мужчины прибавляют в весе гораздо более стремительно, чем женщины. Процент мужчин с ожирением в нашей стране за период с 1993 по 2003 г. увеличился в три раза и составляет $26,9 \%[2]$.

Каковы же основные причины ожирения? Основными причинами на сегодняшний день являются неправильная система питания и гиподинамия: избыточное энергопотребление на фоне низких энергозатрат неминуемо 
приводит к развитию экзогенно-конституционального ожирения. Современный человек потребляет гораздо больше килокалорий, чем может потратить. На долю вторичного ожирения, то есть ожирения при различных заболеваниях (генетических, эндокринных, заболеваний ЦНС и др.), включая и ятрогенное ожирение, приходится не более $5 \%$ случаев.

Зачастую лица с ожирением воспринимают избыточную массу тела не более как эстетическую проблему, не осознавая, насколько серьезными могут быть последствия. Так, ожирение является фактором риска развития целого ряда заболеваний - сахарного диабета 2 типа, артериальной гипертензии, ишемической болезни сердца, неалкогольной жировой болезни печени, гастроэзофагеальной рефлюксной болезни, синдрома обструктивного апноэ сна, различных нарушений репродуктивной функции у мужчин и женщин, некоторых онкологических заболеваний (рак молочной железы, эндометрия, колоректальный рак), поражений опорно-двигательного аппарата и др.

\section{ОЖИРЕНИЕ И НАРУШЕНИЯ УГЛЕВОДНОГО ОБМЕНА}

Ожирение является одним из основных факторов риска развития нарушений углеводного обмена. Сахарный диабет - еще одна глобальная катастрофа в современном мире. По данным Международной Федерации Диабета, на конец 2019 г. зарегистрировано порядка 463 млн больных сахарным диабетом, из них более 90\% - пациенты с сахарным диабетом 2 типа (СД2) [3]. В 2016 г. были оглашены результаты первого национального эпидемиологического кросс-секционного исследования по выявлению распространенности СД2 на территории Россий- ской Федерации, по данным которого, среди взрослого населения России 20-79 лет у 19,3\% выявлен предиабет, у 5,4\% населения диагностирован СД2, при этом у 54\% из них заболевание ранее диагностировано не было. При этом среди лиц с ожирением (ИМТ $\geq 30$ кг/м²) распространенность данных нарушений углеводного обмена составила 33,3\% и 12\% соответственно [4].

Многочисленные эпидемиологические исследования показывают, что риск развития диабета возрастает по мере увеличения массы жировой ткани в организме. Неоспоримым является и тот факт, что именно наличие висцерального (центрального, абдоминального, андроидного) ожирения свидетельствует о высоком риске развития различных кардиометаболических последствий. Поэтому, оценивая статус пациента, важно не только рассчитывать ИМТ, но и определять окружность талии. Критическим размером, в ключе развития осложнений, для представителей европеоидной расы является окружность талии более 84 см у женщин и более 90 см у мужчин.

Основой ассоциации ожирения и нарушений углеводного обмена является развитие вторичной инсулинорезистентности (ИР) на фоне гипертрофии и дисфункции жировых клеток. На протяжении последних десятилетий изучению механизмов влияния избытка жировой ткани на развитие системной резистентности к инсулину посвящены многие научно-исследовательские работы, однако до сих пор не получены ответы на все вопросы. Гиперинсулинемия, неизбежно развивающаяся на фоне ИР, приводит к увеличению массы тела, замыкая порочный круг и вызывая целый спектр других патофизиологических осложнений, включая артериальную гипертензию, гиперлипидемию, атеросклероз и др. (рис. 1).

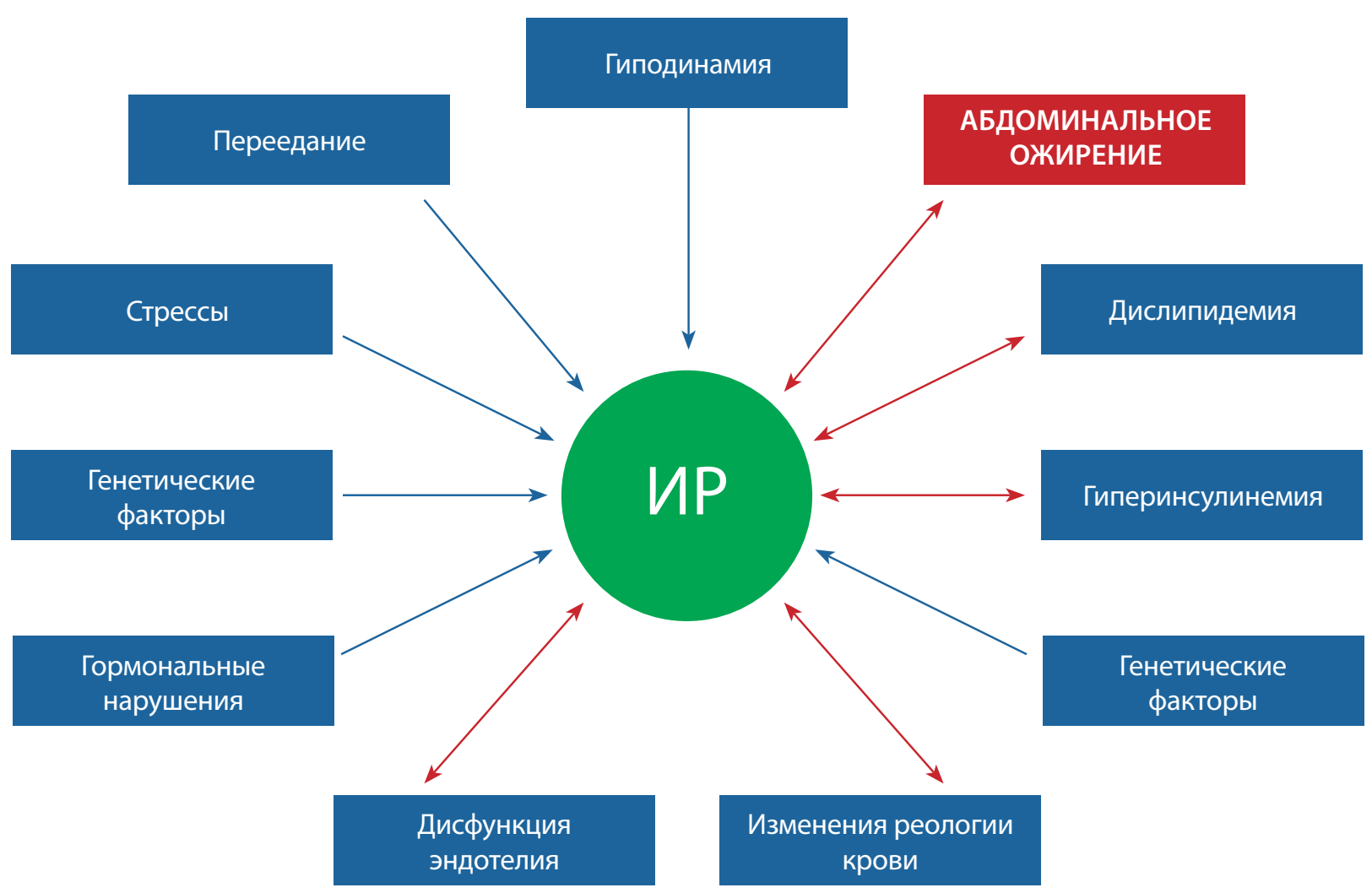

Рисунок 1. Развитие инсулинорезистентности (ИР) 
Для диагностики ИР на сегодняшний день существует около десяти различных методов. Среди них выделяют прямые и непрямые методы оценки ИР. У каждого из них есть свои преимущества и недостатки. Золотым стандартом диагностики ИР считается эугликемический гиперинсулинемический клэмп-тест - наиболее информативный прямой метод диагностики, обладающий высоким уровнем чувствительности и специфичности. Суть метода заключается в увеличении концентрации инсулина в крови путем инфузии инсулина со скоростью 1 МЕ/мин на 1 кг массы тела и одновременном внутривенном введении глюкозы для поддержания уровня гликемии около 5,5 ммоль/л. Количество вводимой глюкозы, необходимое для поддержания указанного уровня гликемии, будет отражать ее инсулинообусловленный метаболизм в тканях. Соответственно, чем больше выражена ИР, тем меньше глюкозы понадобится. Однако данный метод достаточно трудоемок, связан с необходимостью инфузии экзогенного инсулина и сложно выполним в повседневной клинической практике. Широкое применение в клинической практике нашли косвенные методы оценки ИР с использованием специальных расчетных индексов, основанных на соотношении концентраций глюкозы и инсулина как натощак, так и через 2 ч после нагрузки при проведении перорального глюкозотолерантного теста. В нашей стране наиболее часто используется индекс HOMA-IR (homeostasis model assessment), предложенный в 1985 г. [5]: уровень инсулина натощак (мкЕд/л) $\times$ уровень глюкозы плазмы натощак (ммоль/л) / 22,5. Уровень индекса HOMA-IR более 2,7 свидетельствует о наличии ИР. Четких критериев интерпретации HOMA-IR нет, в исследованиях можно встретить разные показатели отрезной точки (75 перцентиль кумулятивного популяционного распределения), но всегда следует учитывать - чем выше данный индекс ИР, тем более выражена ИР. Еще один индекс ИР основан на показателях липидного спектра - уровень триглицеридов (ТГ) (мг/дл) / уровень холестерина липопротеидов высокой плотности (ХС-ЛПВП) (мг/дл). При использовании указанных единиц измерения расчетный индекс более 3,5 свидетельствует о наличии ИР. Вышеперечисленные математические модели широко применяются в практике, однако, в силу своей вариабельности, не могут быть использованы для рутинного скрининга.
В последние годы активно изучаются новые подходы к определению ИР. В частности, В 2007 г. был предложен индекс ИР с участием адипонектина (HOMA-AD) - соотношение HOMA-IR и уровня адипонектина. В качестве порогового значения, свидетельствующего об ИР, принято считать уровень HOMA-AD более 0,95 [6].

В 2014 г. опубликованы данные о применении нового метаболического индекса (МИ) для определения ИР, где учтены не только показатели углеводного обмена, но и уровень ТГ и ХС-ЛПВП натощак. МИ = ТГ (ммоль/л) $\times$ глюкоза (ммоль/л) / ХС-ЛПВП (ммоль/л). ИР диагностируется при уровне МИ 7,0 и более [7].

\section{ИНСУЛИН-ИНДУЦИРОВАННЫЙ МЕТАБОЛИЗМ ГЛЮКОЗЫ В НОРМЕ И ПРИ ОЖИРЕНИИ}

Инсулин является гормоном, оказывающим влияние на все виды обмена, с выраженным анаболическим эффектом. В рамках жирового обмена под действием инсулина стимулируются поступление глюкозы в адипоциты, образование жирных кислот, триглицеридов и глицерофосфата; подавляется липолиз. Эффекты инсулина реализуются посредством целого ряда каскадных реакций при активации инсулиновых рецепторов. Количество данных рецепторов в клетках различно, больше всего инсулиновых рецепторов в гепатоцитах, адипоцитах и миоцитах. Рецептор состоит из двух альфа-субъединиц, обладающих сродством к инсулину, и двух каталитических бета-субъединиц, обладающих тирозин-протеинкиназной активностью. Активированный инсулиновый рецептор взаимодействует с цитоплазматическими белками субстратами инсулиновых рецепторов (insulin-receptor substrate - IRS), основными из них являются IRS-1 и IRS-2. От степени выраженности фосфорилирования субстрата зависит степень чувствительности клетки к инсулину. Посредством субстрата инсулин активирует фосфатидилинозитол-3-киназу, которая, в свою очередь, стимулирует транслокацию основного переносчика глюкозы - GLUT4 (Glucose transporter type 4) - из цитоплазмы на мембрану, при участии которого и осуществляется трансмембранный перенос глюкозы в клетки (рис. 2). Кроме того, в жировых клетках активация фосфатидилинозитол-3-киназы инсулином приводит к ингибированию липолиза [8].

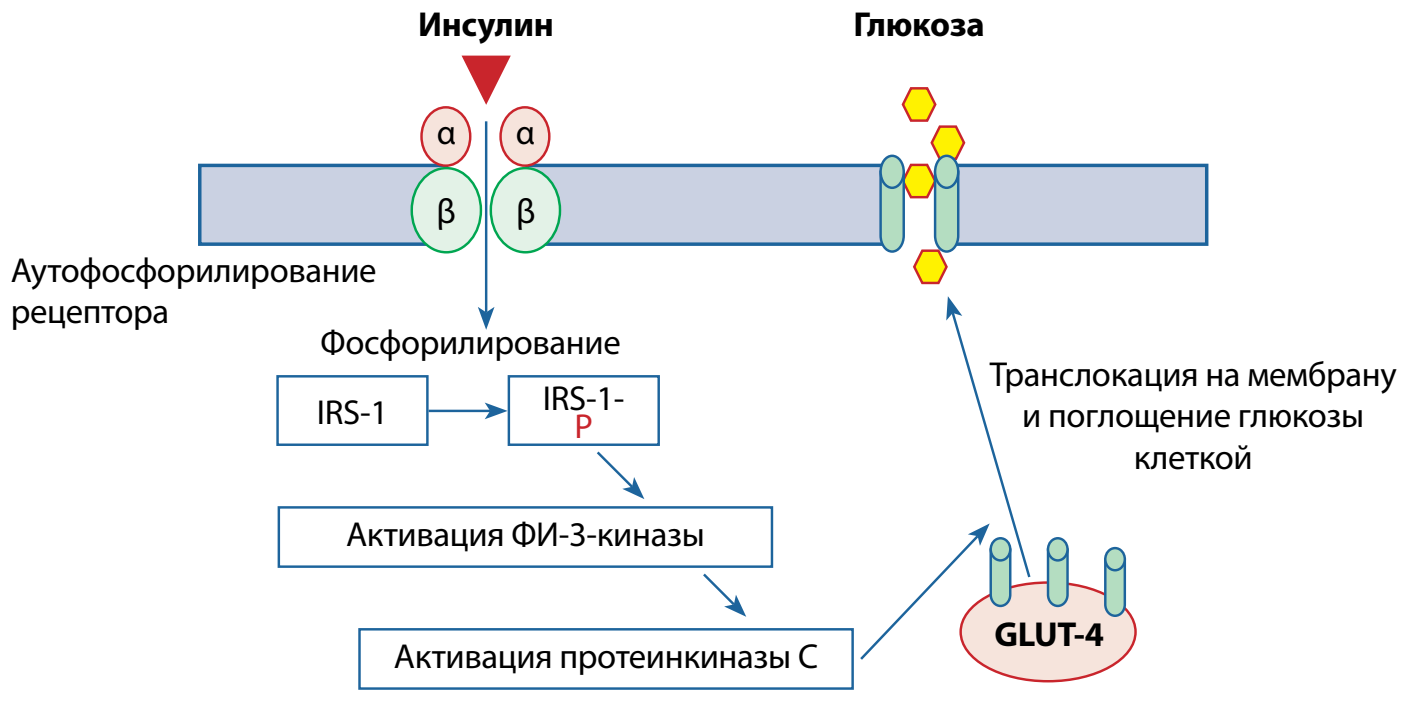

Рисунок 2. Трансмембранный перенос глюкозы 


个ИЛ-6, ИЛ-8,
个ингибитор АП-1, ФНО-а,
моноцитарный ХП-1

个активных форм кислорода (супероксидные $\mathrm{R}$ и $\mathrm{H}_{2} \mathrm{O}_{2}$ )

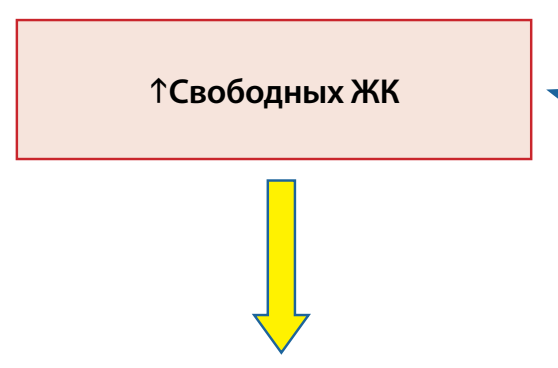

\section{$\downarrow$ Адипонектина}

个Лептина

компонента С3-комплемента (стимуляция роста адвентициальных фибробластов)

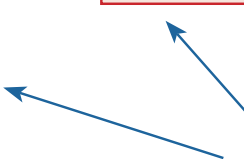

фибобластов)

Хроническое медленно прогрессирующее воспаление $\rightarrow$ инсулинорезистентность,

个апоптоз $\beta$-клеток, $\downarrow$ секреция инсулина,

оксидативный стресс, $\uparrow$ клеточная пролиферация, $\downarrow$ вазорелаксирующих свойств ПВЖТ; дисфункция эндотелия; ригидность сосудистой стенки; вазоконстрикция

(сократительная активность ГМК сосудов)

个висфатина

(ФР и миграции ГМК сосудов)

$\uparrow Ф$-р роста гепатоцитов

(стимуляция пролиферации эндотелия)

个Ангиотензиногена $\rightarrow$ Ангиотензина II

Гипертрофия

и гиперплазия адипоцита

при ожирении

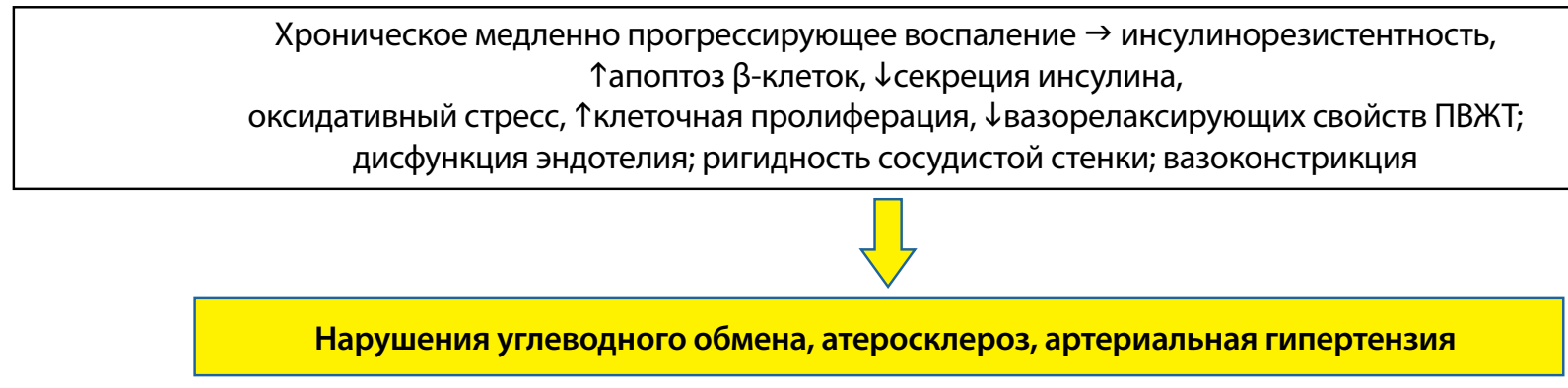

Рисунок 3. Дисбаланс секреции метаболитов жировой ткани при ожирении и его последствия

Значительное увеличение размеров и гиперплазия адипоцитов при ожирении сопровождаются выраженными изменениями их секреторной активности: дисбалансом секреции адипокинов, увеличением секреции провоспалительных цитокинов, свободных жирных кислот (СЖК), активных форм кислорода и других метаболитов. Все это приводит к развитию хронического медленно прогрессирующего воспаления, оксидативного стресса, дисфункции эндотелия и др. В результате увеличивается риск развития СД2, атеросклероза, артериальной гипертензии (рис. 3) [9-12].

ИР при ожирении проявляется в снижении индуцированного инсулином транспорта и метаболизма глюкозы в адипоцитах, скелетных мышцах и печени [13]. Эти функциональные дефекты частично вызваны нарушением трансдукции инсулинового сигнала во всех тканях-мишенях, вследствие ингибирования транслокации и регуляции действия GLUT4, уменьшения количества инсулиновых рецепторов в миоцитах и адипоцитах, нарушения аутофосфорилирования рецепторов, снижения активности тирозинкиназы и фосфорилирования IRS. Также одними из механизмов развития сигнальных дефектов при ожирении могут быть повышенная экспрессия и активность нескольких белковых тирозинфосфатаз, возрастающие на фоне хронического воспаления, которые дефосфорилируют субстраты инсулиновых рецепторов и, таким образом, прекращают передачу сигналов, что, в свою очередь, способствует развитию ИР.

В некоторых работах показана взаимосвязь между уровнем адипонектина и развитием ИР. В одних - прослеживалась обратная связь между уровнем адипонектина и показателями индекса ИР HOMA-IR, ИМТ и окружностью талии [14]. В других - было продемонстрировано, что у пациентов с нарушенной толерантностью к глюкозе (НТГ) или СД2 уровень адипонектина существенно ниже [15]. Кроме того, есть данные о влиянии лептина на секрецию инсулина при ожирении и ИР. Результаты ряда работ демонстрируют положительную корреляцию степени выраженности гиперлептинемии и ИР у лиц с различным ИМТ [16]. Описанные результаты позволяют судить о том, что дисбаланс секреции адипокинов вносит существенный вклад в развитие ИР при ожирении.

В снижении чувствительности к инсулину в разных тканях ведущая роль принадлежит различным механизмам. В адипоцитах преобладает снижение плотности инсулиновых рецепторов, в мышечной ткани - снижение тирозинкиназной активности, что приводит к нарушению поглощения глюкозы, угнетается антилиполитическое влияние инсулина, растет уровень СЖК; значительно активизируются гликогенолиз и глюконеогенез.

Именно ИР является одним из важнейших звеньев патогенеза целого ряда основных, ассоциированных с ожирением метаболических и гемодинамических нарушений, в патогенезе которых дисфункция жировой ткани и ИР тесно переплетены.

\section{ИНСУЛИНОРЕЗИСТЕНТНОСТЬ, ДИСЛИПИДЕМИЯ И СЕРДЕЧНО-СОСУДИСТЫЕ ЗАБОЛЕВАНИЯ}

В настоящее время собрана широкая доказательная база близкой взаимосвязи ИР, гиперинсулинемии и артериальной гипертензии (АГ). По данным некоторых авторов, до 58\% пациентов с АГ имеют ИР той или иной степени выраженности [17]. Есть данные, что ИР является независимым фактором риска развития АГ и у людей с нормальной массой тела и может являться 
первым предиктором ее развития [18]. При ожирении ИР усугубляет развитие воспалительной реакции, усиливает гиперактивацию симпатоадреналовой системы, ренин-ангиотензин-альдостероновой системы, способствует увеличению объема циркулирующей крови на фоне повышения реабсорбции ионов натрия в почечных канальцах, что приводит к возрастанию сердечного выброса и повышению общего периферического сопротивления сосудов [19]. В условиях развивающейся дисфункции эндотелия на фоне ожирения гиперинсулинемия приводит к подавлению синтеза оксида азота (NO), простациклина и увеличению синтеза вазоконстрикторов.

Хроническое воспаление, снижение синтеза NO, вазоконстрикция, оксидативный стресс оказывают существенное влияние на развитие атеросклероза. Во многих работах продемонстрировано увеличение частоты и выраженности атеросклеротического поражения коронарных артерий на фоне ИР и гиперинсулинемии. Результаты исследований показывают, что ИР способствует развитию ишемической болезни сердца и осложнений, в частности, острого инфаркта миокарда, влияя на их исход [20]. Известно, что дисбаланс секреции активных метаболитов жировой ткани существенно влияет на коагуляцию крови. Развившаяся ИР и гиперинсулинемия усугубляют эти нарушения, приводят к увеличению уровня фибриногена и повышению активности ингибитора тканевого активатора плазминогена-1 [21]. Снижение фибринолитической активности способствует развитию тромбозов и формированию атеросклеротической бляшки, что значительно увеличивает сердечно-сосудистые риски у таких пациентов.

Снижение чувствительности миоцитов к инсулину захватывает все типы мышечной ткани, в том числе и кардиомиоциты. Прогрессирование ИР в миокарде усугубляет дисфункцию и изменение морфологии митохондрий при ожирении, приводит к снижению энергетического запаса в кардиомиоцитах, к увеличению риска развития дисфункции левого желудочка на фоне увеличения объема циркулирующей крови и хронической стимуляции симпатической нервной системы [22]. Отмечено, что ИР усугубляет развитие дислипидемии при ожирении. При ИР возрастает уровень триглицеридов (ТГ), липопротеинов очень низкой плотности (ЛПОНП), снижается уровень липопротеинов высокой плотности (ЛПВП), умеренно повышается уровень липопротеинов низкой плотности (ЛПНП). Субстратом для избыточного образования ТГ являются СЖК, синтез которых увеличен при ожирении и ИР. Помимо избыточного синтеза СЖК на фоне избытка жировой ткани и ИР, эти изменения также связаны с нарушением регулирующих влияний инсулина на липидный обмен. В условиях ИР и гиперинсулинемии происходит изменение активности ферментов - липопротеинлипазы и печеночной триглицеридлипазы, приводящее к увеличению синтеза и секреции ЛПОНП и замедлению их удаления из кровотока. Кроме того, подавляется ингибирующее влияние инсулина на высвобождение ЛПОНП в печени, вследствие чего нарушается баланс между синтезом и элиминацией ЛПОНП. В свою очередь, дислипидемия усиливает инсулинорезистентность. Известно, что высокий уровень ЛПНП способствует снижению числа рецепторов к инсулину [23].

\section{ИНСУЛИНОРЕЗИСТЕНТНОСТЬ И НЕАЛКОГОЛЬНАЯ ЖИРОВАЯ БОЛЕЗНЬ ПЕЧЕНИ}

Как уже упоминалось, печень также является одним из основных органов-мишеней для действия инсулина, функция которого значительно страдает при развитии ожирения и ИР. И еще одним ассоциированным с ожирением заболеванием, имеющим в своем патогенезе тесную взаимосвязь с ИР и носящим характер глобальной эпидемии, является неалкогольная жировая болезнь печени (НАЖБП). Данные эпидемиологических исследований существенно варьируют в зависимости от используемого метода диагностики. По данным первого российского эпидемиологического исследования-наблюдения DIREG L 01903, распространенность НАЖБП в Российской Федерации в 2007 г. составила 27\%, в том числе 80,3\% случаев приходилось на стеатоз печени, 16,8\% на неалкогольный стеатогепатит и 2,9\% - на цирроз печени. Показано увеличение частоты выявления НАЖБП с возрастом, с максимальной распространенностью среди лиц 50-59 лет - 31,1\% [24]. Другие исследования демонстрируют, что среди лиц с ожирением выявляемость НАЖБП составляет до 100\% [25]. Выделяют три основные формы НАЖБП, которые отображают и стадийность развития заболевания: стеатоз печени, неалкогольный стеатогепатит, цирроз печени. Зачастую НАЖБП протекает бессимптомно или сопровождается неспецифическими жалобами. В случае если развивается цирроз печени, на первый план выходит симптоматика печеночной недостаточности, портальной гипертензии.

Патогенез НАЖБП является сложным многокомпонентным процессом, в основе которого лежит развитие ИР, накопление триглицеридов и других производных холестерина в гепатоцитах. Ожирение и ИР способствуют образованию избыточного количества СЖК, замедлению их высвобождения и утилизации из печени, что приводит к их избыточному накоплению в печени. Ввиду высокого уровня СЖК активизируются процессы перекисного окисления, что приводит к накоплению активных форм кислорода, повреждению митохондрий, дефициту АТФ, избыточной продукции фактора некроза опухоли альфа, развитию хронического воспалительного процесса и печеночной ИР. В результате чего инициируется гибель гепатоцитов и парадоксально увеличивается продукция глюкозы печенью, несмотря на имеющуюся гиперинсулинемию. На сегодняшний день доказана корреляция между показателями ИР и признаками поражения печени: уровнем инсулина сыворотки крови и наличием признаков цитолиза; увеличением индекса HOMA-IR и выраженностью фиброза печени, что продемонстрировано во многих клинических исследованиях [26]. Кроме того, известно, что запущенный цикл патологических процессов при НАЖБП стимулирует развитие ИР, способствует атерогенезу и существенно увеличивает сердечно-сосудистые риски (рис. 4).

\section{ИНСУЛИНОРЕЗИСТЕНТНОСТЬ И НАРУШЕНИЯ РЕПРОДУКТИВНОЙ ФУНКЦИИ ПРИ ОЖИРЕНИИ}

Еще одной острой проблемой является нарушение репродуктивной функции как у женщин, так и у мужчин с ожирением и ИР. Различные нарушения менструаль- 


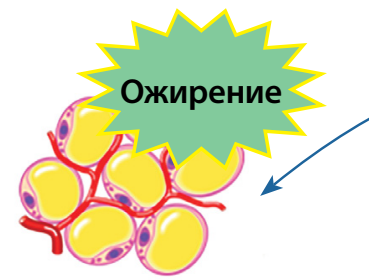

Дисбаланс секреции адипокинов १провоспалительных цитокинов Оксидативный стресс 个СЖK
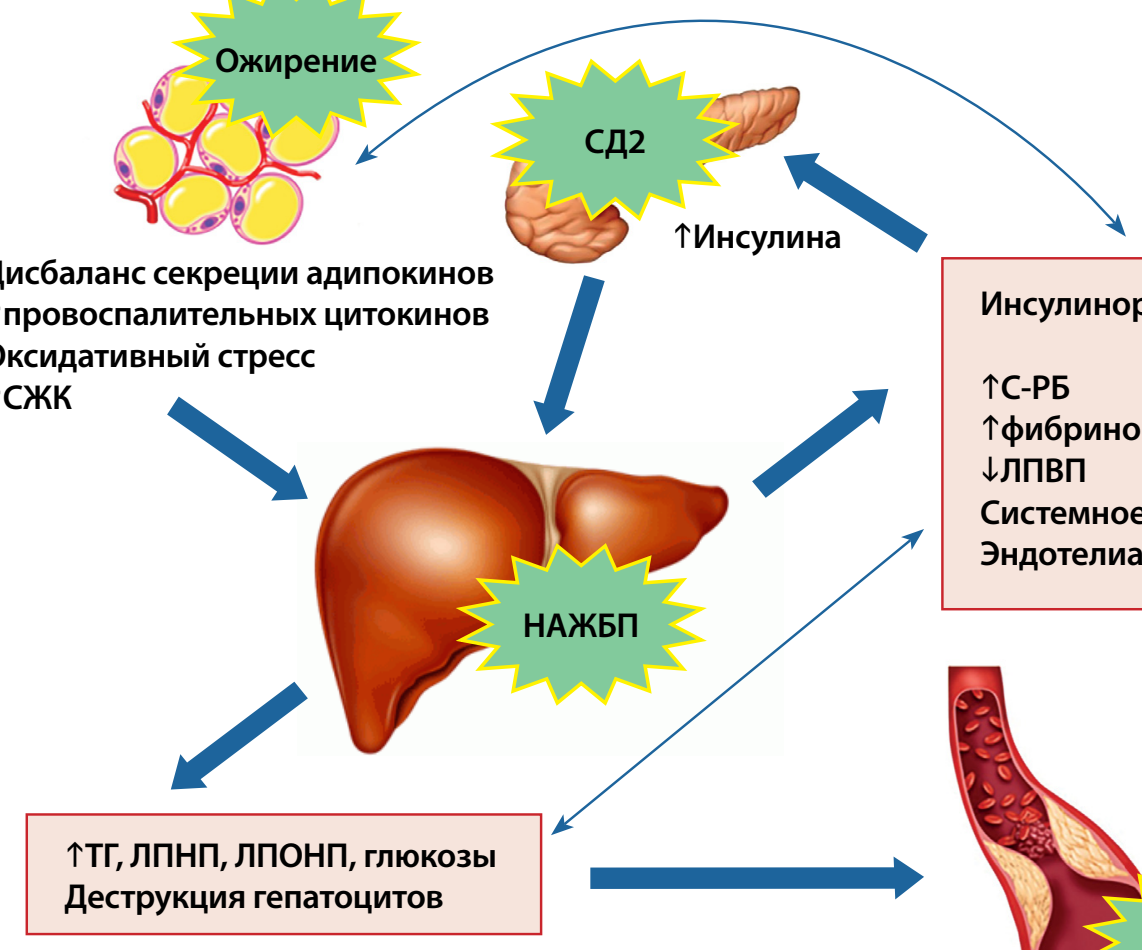

Инсулинорезистентность

१С-РБ

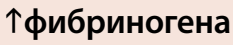
$\downarrow Л П В П$

Системное воспаление

Эндотелиальная дисфункция

Рисунок 4. Формирование порочного круга метаболических и гемодинамических нарушений при ожирении.

ного цикла, в том числе ановуляторный менструальный цикл, у женщин с ожирением встречаются в 3-5 раз чаще, чем у женщин с нормальной массой тела. Помимо известных дисгормональных нарушений на фоне избытка жировой ткани, ИР усугубляет развитие гиперандрогении у женщин с ожирением, способствует прогрессированию синдрома поликистозных яичников (СПКЯ), что может являться причиной нарушений овуляторного цикла и привести к бесплодию. Распространенность ожирения и ИР среди женщин с СПКЯ составляет 65\% [27]. Гиперинсулинемия стимулирует синтез яичниковых андрогенов, а также ингибирует секрецию глобулинов, связывающих половые гормоны (ГСПГ) в печени, что приводит к увеличению циркуляции свободных андрогенов в кровотоке. Патологическая ИР при беременности может стать причиной развития гестационного СД, артериальной гипертензии, привести к прерыванию беременности. Увеличивается риск осложнений и в неонатальном периоде, что связано с нарушениями развития плода, - гипертрофия и гипотрофия плода встречается у женщин с патологической ИР в 2 и в 3 раза чаще соответственно, чем у здоровых женщин [28].

Значительное негативное влияние ожирение оказывает и на репродуктивный потенциал мужчин. Вследствие гиперлептинемии, увеличения уровня ароматазы и, соответственно, конверсии андрогенов в эстрогены в жировой ткани, у мужчин с ожирением развивается андрогенный дефицит. Кроме того, хроническое медленно прогрессирующее системное воспаление, оксидативный стресс, в свою очередь, оказывают непосредственное действие на морфологию, количество и подвижность сперматозоидов. Перечисленные процессы являются основными ключевыми механизмами в развитии бесплодия у мужчин с ожирением. Взаимосвязь высокого ИМТ и частоты бесплодия у мужчин про- демонстрирована в большом количестве исследований $[29,30]$ и на сегодняшний день, не вызывает сомнений. Гипогонадизм у мужчин с ожирением усугубляет ИР, увеличивает риск развития СД и вносит значительный вклад в развитие метаболических нарушений и увеличение массы тела, замыкая тем самым патологический порочный круг.

\section{ОСНОВНЫЕ ПРИНЦИПЫ ТЕРАПИИ ПРИ СИНДРОМЕ ИНСУЛИНОРЕЗИСТЕНТНОСТИ}

Ключевым аспектом лечения ИР при ожирении является снижение массы тела. В основе терапии лежит сбалансированное питание, индивидуальный подбор калорийности суточного рациона и борьба с гиподинамией. Важно, чтобы расход энергии превышал энергопотребление при сохранении полноценности и разнообразия питания. В комплексе с немедикаментозными методами,

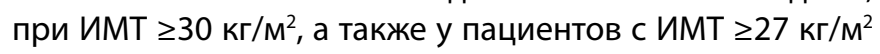
при наличии осложнений возможно применение лекарственных препаратов для снижения массы тела. В Российской Федерации на сегодняшний день зарегистрировано три таких препарата - орлистат, сибутрамин и лираглутид 3,0 мг. Каждый из препаратов имеет свой механизм действия, должен применяться строго в соответствии с инструкцией и с учетом противопоказаний. При морбидном ожирении и в случае ИМТ $\geq 35$ кг/м² при наличии осложнений возможно оперативное лечение с применением различных методов бариатрической хирургии. Препараты, снижающие ИР (бигуаниды, тиазолидиндионы, ингибиторы ангиотензинпревращающего фермента) применяются только в случае диагностированного предиабета, СД2, АГ, а при изолированной ИР на фоне ожирения без указанных проявлений их использовать не рекомендуется. 


\section{ЗАКЛЮЧЕНИЕ}

Таким образом, ИР, развивающаяся на фоне избыточной массы тела и ожирения, является, с одной стороны, независимым, а с другой - усугубляющим фактором развития таких ассоциированных с ожирением заболеваний, как СД, ишемическая болезнь сердца, АГ, НАЖБП и др., находящихся в тесной патогенетической взаимосвязи друг с другом. Формируется порочный круг, разорвать который необходимо на ранних стадиях проявлений. И, несмотря на то, что в настоящее время хорошо развиты медикаментозные методы лечения, важно понимать, что фундаментом терапии и основой профилактики ожирения и нарушений углеводного обмена является модификация образа жизни (изменение системы питания и расширение режима физической активности). Формирование культуры питания имеет огромное значение на всех уровнях профилактики и лечения данных заболеваний. Поэтому сегодня все силы мирового здравоохранения направлены на реализацию этой цели, формирование среди населения приверженности к здоровому образу жизни и ответственности за собственное здоровье.

\section{ДОПОЛНИТЕЛЬНАЯ ИНФОРМАЦИЯ}

Источник финансирования. Подготовка и публикация рукописи проведены на личные средства авторского коллектива.

Конфликт интересов. Авторы работы сообщают, что потенциальных и явных конфликтов интересов (финансовые отношения, служба или работа в учреждениях, имеющих финансовый или политический интерес к публикуемым материалам, должностные обязанности и др.), связанных с рукописью, не существует.

Участие авторов. Все авторы внесли значимый вклад в подготовку статьи, прочли и одобрили финальную версию статьи перед публикацией.

\section{СПИСОК ЛИТЕРАТУРЫ | REFERENCES}

1. Who.int [Internet]. Obesity and overweight [cited 2018 Jun 30]. Available from: http://www.who.int/mediacentre/factsheets/fs311/en/.

2. Муромцева Г.А., Концевая А.В., Константинов В.В., и др. Распространенность факторов риска неинфекционных заболеваний в российской популяции в 2012-2013 гг. Результаты исследования ЭССЕ-РФ. // Кардиоваскулярная терапия и профилактика. — 2014. - Т. 13. — № 6. C. 4-11. [Muromtseva GA, Kontsevaya AV, Konstantinov VV, et. al. The prevalence of non-infectious diseases risk factors in Russian population in 2012-2013 years. The results of ECVD-RF. Cardiovascular therapy and prevention. 2014;13(6):4-11. (In Russ.)] doi: http://doi.org/10.15829/1728-8800-2014-6-4-11

3. International Diabetes Federation. IDF Diabetes Atlas. 9th ed. Brussels: IDF; 2019

4. Дедов И.И., Шестакова М.В., Галстян Г.Р. Распространенность сахарного диабета 2 типа у взрослого населения России (исследование NATION). // Сахарный диабет. — 2016. T. 19. — №2. - C. 104-112. [Dedov II, Shestakova MV, Galstyan GR. The prevalence of type 2 diabetes mellitus in the adult population of Russia (NATION study). Diabetes mellitus. 2016;19(2):104-112. (In Russ.)] doi: https://doi.org/10.14341/DM2004116-17

5. Matthews DR, Hosker JP, Rudenski AS, et al. Homeostasis model assessment: insulin resistance and beta-cell function from fasting plasma glucose and insulin concentrations in man. Diabetologia. 1985;28(7):412-419. doi: https://doi.org/10.1007/bf00280883

6. Vilela BS, Vasques AC, Cassani RS, et al. The HOMAAdiponectin (HOMA-AD) Closely Mirrors the HOMA-IR Index in the Screening of Insulin Resistance in the Brazilian Metabolic Syndrome Study (BRAMS). PLoS One. 2016;1 1(8):e0158751. doi: https://doi.org/10.1371/journal.pone.0158751

7. Ройтберг Г.Е., Дорош Ж.В., Шархун О.О., и др. Возможности применения нового метаболического индекса при оценке инсулинорезистентности в клинической практике. // Рациональная фармакотерапия в кардиологии. - 2014 — T. 10. — №3. - C. 264-274. [Roytberg GE, Dorosh JV, Sharkhun $\mathrm{OO}$, et al. New metabolic index use potentialities in evaluation of insulin resistance in clinical practice. Rational pharmacotherapy in cardiology. 2014;10(3):264-274. (In Russ.)] doi: https://doi.org/10.20996/1819-6446-2014-10-3-264-274

8. Николаев А.Я., Осипов Е.В., Кцоева С.А. Биохимия инсулинозависимого сахарного диабета. - М.: Медицина; 2000. [Nikolaev AY, Osipov EV, Ktsoeva SA. Biokhimia insulinozavisimogo sakharnogo diabeta. Moscow: Meditsina; 2000. (In Russ.)]

9. Britton KA, Pedley A, Massaro JM, et al. Prevalence, distribution, and risk factor correlates of high thoracic periaortic fat in the Framingham Heart Study. J Am Heart Assoc. 2012;1 (6):e004200. doi: https://doi.org/10.1161/JAHA.112.004200

10. Cheng KH, Chu CS, Lee KT, et al. Adipocytokines and proinflammatory mediators from abdominal and epicardial adipose tissue in patients with coronary artery disease. Int J Obes (Lond). 2008;32(2):268-274. doi: https://doi.org/10.1038/sj.ijo.0803726

11. Дедов И.И., Мельниченко Г.А., Бутрова С.А. Жировая ткань как эндокринный орган. // Ожирение и метаболизм. 2006. — T. 3. — №1. - C. 6-13. [Dedov II, Mel'nichenko GA, Butrova SA. Zhirovaya tkan' kak endokrinnyy organ. Obesity and metabolism. 2006;3(1):6-13. (In Russ.)] doi: https://doi.org/10.14341/2071-8713-49375

12. Szasz T, Bomfim GF, Webb RC. The influence of perivascular adipose tissue on vascular homeostasis. Vasc Health Risk Manag. 2013;9:105-116. doi: https://doi.org/10.2147/NHRM.S33760

13. Reaven GM. Pathophysiology of insulin resistance in human disease. Physiol Rev. 1995;75(3):473-486. doi: https://doi.org/10.1152/physrev.1995.75.3.473

14. Baratta R, Amato S, Degano C, et al. Adiponectin relationship with lipid metabolism is independent of body fat mass: evidence from both cross-sectional and intervention studies. J Clin Endocrinol Metab. 2004;89(6):2665-2671. doi: https://doi.org/10.1210/jc.2003-031777

15. Скудаева Е.С., Пашенцева А.В., Вербовой А.Ф. Уровни резистина, адипонектина и инсулинорезистентности у пациентов с разной степенью нарушений углеводного обмена. // Ожирение и метаболизм. - 2011. - Т. 8. - №3. - C. 57-60. [Skudaeva ES, Pashentseva AV, Verbovoy AF. Urovni resistina, adiponektina I insulinorezistentnosti u patsientov s raznoy stepen 'u narusheniy uglevodnogo obmena. Obesity and metabolism. 2011;8(3):57-60. (In Russ.)]

16. Osegbe I, Okpara H, Azinge E. Relationship between serum leptin and insulin resistance among obese Nigerian women. Ann Afr Med. 2016;15(1):14-19. doi: https://doi.org/10.4103/1596-3519.158524

17. Bonora E, Kiechl S, Willeit J, et al. Prevalence of insulin resistance in metabolic disorders: the Bruneck Study. Diabetes. 1998;47(10):1643-1649. doi: https://doi.org/10.2337/diabetes.47.10.1643

18. Skarfors ET, Lithell HO, Selinus I. Risk factors for the development of hypertension: a 10-year longitudinal study in middle-aged men. J Hypertens. 1991;9(3):217-223. doi: https://doi.org/10.1097/00004872-199103000-00004

19. Корнеева О.Н., Драпкина О.М. Патогенетические взаимосвязи артериальной гипертензии и инсулинорезистентности. // Российский кардиологический журнал. - 2006. - Т. 11. №5. - C. 100-103. [Korneeva ON, Drapkina OM. Pathogenetic interaction of arterial hypertension and insulin resistance. Russian journal of cardiology. 2006;1 1(5):100-103. (In Russ.)]

20. Груздева О.В., Каретникова В.Н., Учасова Е.Г., и др. Инсулинорезистентность и риск неблагоприятного исхода через 1 год после перенесенного инфаркта миокарда. // Врач. 2015. - №12. - C. 30-34. [Gruzdeva OV, Karetnikova VN, Uchasova $\mathrm{EG}$, et. al. Insulin resistance and a risk for poor outcome one year after myocardial infarction. Vrach. 2015;(12):30-34. (In Russ.)] 
21. Potter van Loon BJ, Kluft C, Radder JK, et al. The cardiovascular risk factor plasminogen activator inhibitor type 1 is related to insulin resistance. Metabolism. 1993;42(8):945-949. doi: https://doi.org/10.1016/0026-0495(93)90005-9

22. Hu P, Zhang D, Swenson $L$, et al. Minimally invasive aortic banding in mice: effects of altered cardiomyocyte insulin signaling during pressure overload. Am J Physiol Heart Circ Physiol. 2003;285(3):H1261-1269. doi: https://doi.org/10.1152/ajpheart.00108.2003

23. Despres JP, Lamarche B, Mauriege P, et al. Hyperinsulinemia as an independent risk factor for ischemic heart disease. N Engl J Med. 1996;334(15):952-957. doi: https://doi.org/10.1056/NEJM199604113341504

24. Драпкина О.М., Ивашкин В.Т. Эпидемиологические особенности неалкогольной жировой болезни печени в России (результаты открытого многоцентрового проспективного исследования наблюдения DIREGL 01903). // Российский журнал гастроэнтерологии, гепатологии, колопроктологии. - 2014. T. 24. — №4. - C. 32-38. [Drapkina OM, Ivashkin VT. Epidemiologicheskie osobennosti nealkogol'noy zhirovoy bolezni pecheni v Rossii (rezul'taty otkrytogo mnogotsentrovogo prospektivnogo issledovaniya nablyudeniya DIREGL 01903). Russian journal of gastroenterology, hepatology, coloproctology. 2014;24(4):32-38 (In Russ.)]
25. Adams LA, Angulo P, Lindor KD. Nonalcoholic fatty liver disease. CMAJ. 2005;172(7):899-905. doi: https://doi.org/10.1503/cmaj.045232

26. Targher G, Marchesini G, Byrne CD. Risk of type 2 diabetes in patients with non-alcoholic fatty liver disease: Causal association or epiphenomenon? Diabetes Metab. 2016;42(3):142-156. doi: https://doi.org/10.1016/j.diabet.2016.04.002

27. Pasquali R, Gambineri A, Pagotto U. The impact of obesity on reproduction in women with polycystic ovary syndrome. BJOG. 2006;113(10):1148-1159. doi: https://doi.org/10.1111/j.1471-0528.2006.00990.x

28. Шибанова Е.И. Клинико-иммунологические аспекты инсулинорезистентности во время беременности: Авторе $\phi$ дис. ... канд. мед. наук. — М., 2009. [Shibanova El. Klinikoimmunologicheskie aspekty insulinorezistentnosti vo vremya beremennosti. [dissertation] Moscow; 2009. (In Russ.)]

29. Ohwaki K, Endo F, Yano E. Relationship between body mass index and infertility in healthy male Japanese workers: a pilot study. Andrologia. 2009;41(2):100-104. doi: https://doi.org/10.1111/j.1439-0272.2008.00896.x

30. Nguyen RH, Wilcox AJ, Skjaerven R, Baird DD. Men's body mass index and infertility. Hum Reprod. 2007;22(9):2488-2493. doi: https://doi.org/10.1093/humrep/dem139

ИНФОРМАЦИЯ ОБ АВТОРАХ [AUTHORS INFO]:

*Лавренова Евгения Александровна [Evgenia A. Lavrenova, MD]; адрес: Россия, 101990, Москва, Петроверигский пер., д. 10, стр. 3 [address: 10/3 Petroverigskiy Pereulok, 101990 Moscow, Russia]; ORCID: https://orcid.org/0000-0003-1429-8154; Researcher ID: J-3968-2017; eLibrary SPIN: 6440-3431; e-mail: evlavren@gmail.com

Драпкина Оксана Михайловна, д.м.н., профессор [Oxana M. Drapkina, MD, PhD, professor]; ORCID: https://orcid.org/0000-0002-4453-8430; eLibrary SPIN: 4456-1297; e-mail: p310849@gmail.com

*Автор, ответственный за переписку / Corresponding author.

\section{ЦИТИРОВАТЬ:}

Лавренова Е.А., Драпкина О.М. Инсулинорезистентность при ожирении: причины и последствия // Ожирение и метаболизм. - 2020. - Т. 17. - №1. - С. 48-55. doi: https://doi.org/10.14341/omet9759

\section{TO CITE THIS ARTICLE:}

Lavrenova EA, Drapkina OM. Insulin resistance in obesity: pathogenesis and effects. Obesity and metabolism. 2020;17(1):48-55. doi: https://doi.org/10.14341/omet9759 